\title{
Stability Analysis of Cylindrical Tanks under Static and Earthquake Loading
}

\author{
Sukhvarsh Jerath ${ }^{1}$ and Mark Lee ${ }^{2}$ \\ 1. Department of Civil Engineering, University of North Dakota, North Dakota 58202-8115, USA \\ 2. Structural Engineering, Mead \& Hunt, Wisconsin 53562, USA
}

\begin{abstract}
Large thin walled cylindrical above ground tanks have become more susceptible to failure by buckling during earthquakes. In this study, three different geometries of tanks with $H / D$ (height to diameter) ratios of 2.0, 0.56, 1.0, and $D / t$ (depth to thickness) ratios of $960.0,1,706.67$ and 640.0 respectively were analyzed for stability when subjected to the El Centro earthquake at the base. The Budiansky and Roth procedure was used to find the buckling loads when the tanks were empty and when they were filled with liquid up to $90 \%$ of their depth. Also, nonlinear time history analysis using ANSYS finite element computer program was performed. Analysis results show that the dynamic buckling occurs for empty tanks at very high PGA (peak ground accelerations) which are unrealistic even for major earthquakes. Furthermore, when the tanks filled with water up to $90 \%$ of its height, analysis results show that when the $H / D$ ratio reduced by two times (i.e., from 2 to 1 ), the PGA for the buckling increased by six times (increase from $0.25 \mathrm{~g}$ to $1.5 \mathrm{~g}$ ). Hence, $H / D$ ratio plays an important role in the earthquake stability design of over ground steel tanks.
\end{abstract}

Key words: Dynamic stability, earthquake loads, static buckling, storage tanks, structure fluid interaction.

\section{Introduction}

The above ground storage tanks are designed as flat bottom cylindrical vessels with different kinds of roofs. These cylindrical tanks are used to store petroleum products, water, oil, chemicals and so on. The storage tank can leak and contaminate soil and drinking water supplies. Any spill can pose a serious threat to the human health and environment, resulting in substantial cleanup costs. The proper design and detailing of storage tanks is very important from the potential environmental and safety considerations. Large thin walled cylindrical shells used as tanks have become more susceptible to failure by buckling, because the thickness of the shells has reduced due to the availability of high strength materials.

Buckling occurs when a structure under compressive loading undergoes a change in geometry which leads to its ability to resist loads while finding new equilibrium

Corresponding author: Sukhvarsh Jerath, Ph.D., professor, research fields: buckling of cylindrical tanks, impact factors in bridges, durability of concrete pavements and wind turbine towers. E-mail: sukhvarsh.jerath@engr.und.edu. configurations. Lots of previous research was conducted in the area of static buckling [1-3]. In recent years, cylindrical shell buckling under seismic loading has been a subject of great interest because damage in the above ground storage tanks have occurred due to major earthquakes as shown in Fig. 1.

Cooper and Wachholz [4] reported damage of petroleum steel tanks due to the earthquakes of Long Beach (1933), Alaska (1964), San Fernando (1971), Imperial Valley (1979), Loma Prieta (1989), Landers (1992), Northridge (1994), and Kobe (1995). Veletsos and Yang [5], Haroun and Housner [6] studied the effect of hydrodynamic fluid structure interaction on the seismic response. Other investigators have conducted investigations into the response of ground supported isolated tanks and showed that the isolated structure exhibited reduced hydrodynamic pressures [7-10].

Dynamic buckling of the above ground steel storage tanks with conical roofs was investigated by the finite element models having height to diameter ratios of $0.40,0.63$ and 0.95 and liquid level at $90 \%$ of the height 


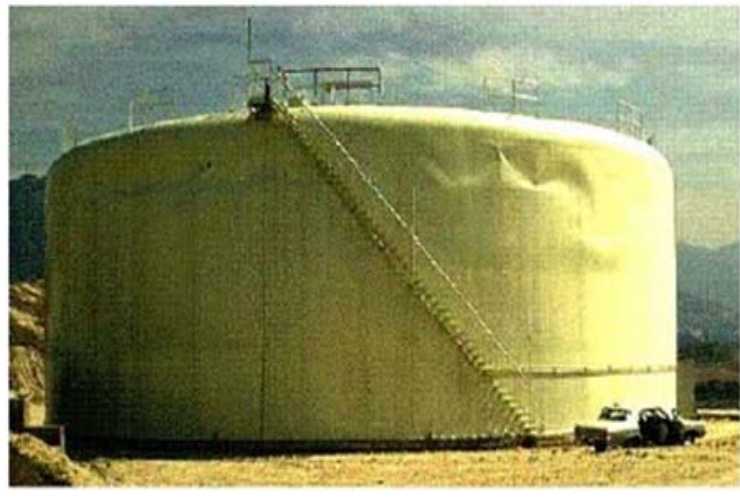

Fig. 1 Earthquake damage of cylindrical tanks.

of the tanks [11]. Accelerograms of 1986 El Salvador and the 1966 Parkfield earthquakes were chosen. It was found that the critical PGA (peak ground acceleration) lied between $0.25 \mathrm{~g}$ to $0.35 \mathrm{~g}$. In another study [12], the research was focused on three tanks due to an earthquake load (1999) in Turkey.

In this study, the structure fluid interaction was incorporated. The final aim of the study is to get design curves giving PGA values for various sizes of cylindrical storage vessels subjected to seismic forces from different earthquakes.

\section{Geometry and Material}

In this study, vertical tanks fixed at the bottom and free at the top of three different sizes, Models A, B, and $\mathrm{C}$, which represent tall and short tanks, were analyzed. Structural steel with material properties of modulus of elasticity, $E=29 \times 10^{6}$ psi $(200,000 \mathrm{MPa})$, Poisson's ratio, $v=0.3$, and mass density, $\rho=7.3386 \times 10^{-4}$ slugs/in. ${ }^{3}\left(7,857 \mathrm{~kg} / \mathrm{m}^{3}\right)$ was used. The dimensions of the three tank models are as follows: Model A: Height $(H)=60 \mathrm{ft}$. $(18.29 \mathrm{~m})$, diameter $(D)=30 \mathrm{ft} .(9.14 \mathrm{~m})$, and thickness $(t)=0.375 \mathrm{in}$. $(9.53 \mathrm{~mm})$ with $H / D=2.0$ and $D / t=960.0$; Model B: Height $(H)=30 \mathrm{ft}$. $(9.14 \mathrm{~m})$, diameter $(D)=53.33 \mathrm{ft}$. $(16.26 \mathrm{~m})$, and thickness $(t)=$ 0.375 in. $(9.53 \mathrm{~mm})$ with $H / D=0.56$ and $D / t=1706.67$; and Model C: Height $(H)=20 \mathrm{ft}$. $(6.1 \mathrm{~m})$, diameter $(D)$ $=20 \mathrm{ft} .(6.1 \mathrm{~m})$, and thickness $(t)=0.375 \mathrm{in} .(9.53 \mathrm{~mm})$ with $H / D=1.0$ and $D / t=640$. The finite element analysis is performed using ANSYS [13] computer program.

\section{Static Buckling Analysis}

\subsection{Verification of the Model}

The accuracy of the finite element model was checked by applying axial compressive force at the top to Model A tank. The boundary conditions for the comparison were changed to the pin-pin ended cylindrical shells. The eigenvalue buckling analysis was performed on the finite element models. The theoretical critical stress $\sigma_{c r}$ for static axial buckling for the pin-pin ended cylindrical shells is given by:

$$
\sigma_{c r}=\frac{E}{\sqrt{3\left(1-v^{2}\right)}}\left(\frac{t}{R}\right)
$$

where, $R$ is the radius of the cylinder. For Model A:

$$
\sigma_{c r}=\frac{29,000,000 \mathrm{psi}}{\sqrt{3\left(1-0.3^{2}\right)}}\left(\frac{0.375 \mathrm{in} .}{180 \mathrm{in} .}\right)=36,566 \mathrm{psi}
$$

The finite element model with a mesh of $48 \times 48$ was made by using ANSYS shell element 181. It is a four-node element with six degrees of freedom at each node: translations in the $x, y$, and $z$ directions and rotations about the $x, y$, and $z$ axes. A compressive pressure vertical line load of $1 \mathrm{lb} / \mathrm{in}$. was applied in ANSYS and a multiplier of 13,904 was obtained. The critical load from the finite element analysis is given by:

$$
\begin{gathered}
\sigma_{\text {crit(ANSYS) }}=\frac{\text { Multiplier }}{t} \\
\frac{13,904 \mathrm{lb} / \text { in. }}{0.375 \mathrm{in} .}=37,077 \mathrm{psi}
\end{gathered}
$$

The error is $\frac{37,077-36,566}{36,566} \times 100 \%=1.4 \%$.

Similarly, the error for Model B was $9.04 \%$. This shows that the finite element model is quite accurate in predicting the static critical load.

\subsection{Eigenvalue Buckling Load}

The finite element eigenvalue buckling analysis was performed to give the static buckling load due to a horizontal shear load applied at the top free surface 
shown in Fig. 2.

One half of the tank was modeled due to symmetry. The first buckling mode shape of cylindrical tank model A is shown in Fig. 3. The eigenvalue buckling

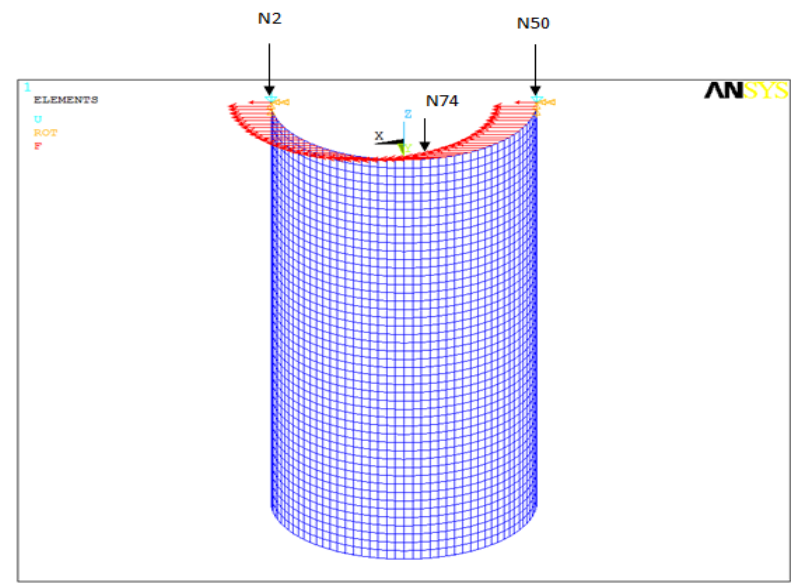

Fig. 2 Shear loads on the cylindrical tank Model $A$ in the finite element analysis.

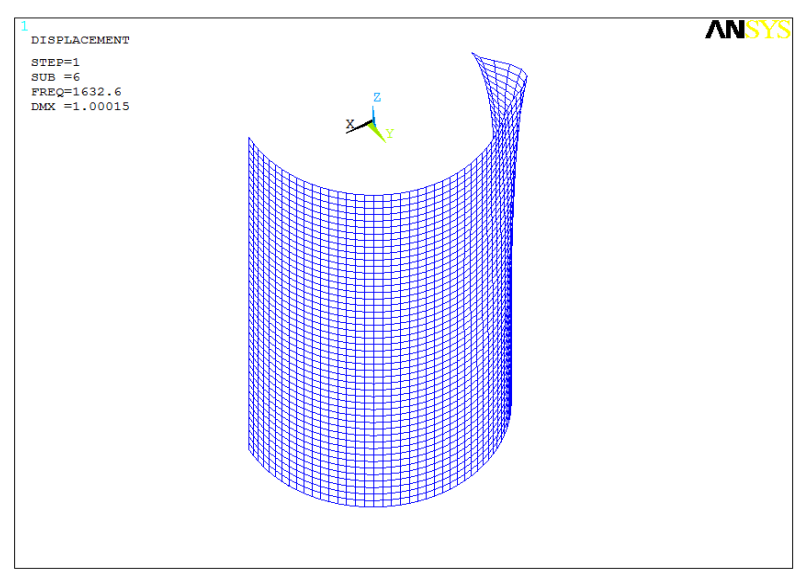

Fig. 3 First buckling mode shape of the cylindrical tank Model A.

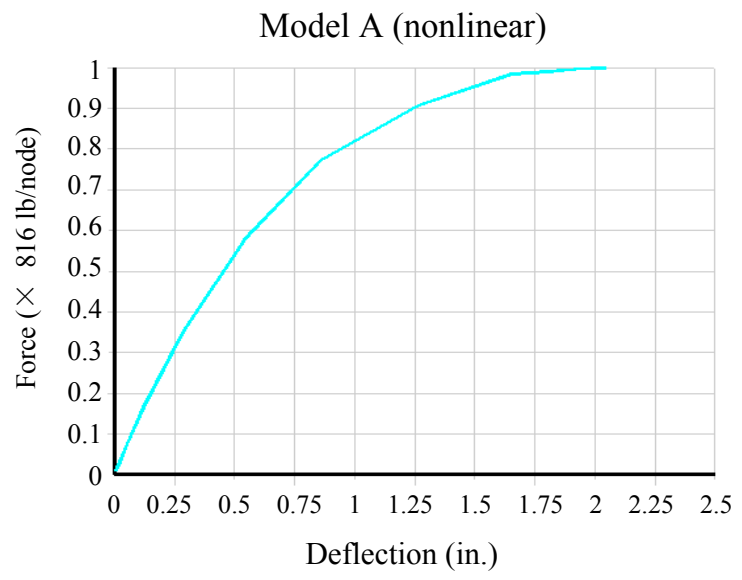

Fig. 4 Load deflection curve for Model A tank. analysis gives an approximate value of the static buckling load that is more than the actual value. This analysis was used to give an idea of the shear buckling load and the node where the maximum deflection occurs to help in the nonlinear static analysis. The load multiplier of 1,646 lbs. (7,321 N) was found. Hence, the buckling load is $1,632 \times 96=156,672 \mathrm{lbs}$. $(7,321 \times$ $96=702,816 \mathrm{~N}$ ) because there are $48 \times 2=96$ nodes on the top perimeter of the tank.

\subsection{Nonlinear Static Buckling Analysis}

Large deflection analysis was performed on the empty tank and the arc length method was used to find the buckling load. The load deflection graph was plotted as shown in Fig. 4. The buckling occurred when the horizontal force of $816 \mathrm{lbs}$. was applied at each node at the top perimeter except at the end nodes where half the force was applied because of symmetry. The total buckling load is $816 \times 96=78,336$ lbs. $(3,672 \times$ $96=352,512 \mathrm{~N})$.

\section{Dynamic Analysis}

\subsection{Modal Analysis}

Modal analysis was performed for each cylindrical model tank. It determines vibration characteristics (natural frequencies and mode shapes) of each model. The natural frequencies and mode shapes are important parameters in the design of a structure for dynamic loading conditions. The equation of motion for an undamped system vibrating freely is given by:

$$
\boldsymbol{M} \ddot{\boldsymbol{u}}+\boldsymbol{K u}=\mathbf{0}
$$

where, $\boldsymbol{M}=$ structural mass matrix, $\boldsymbol{K}=$ structural stiffness matrix, $\ddot{\boldsymbol{u}}=$ nodal acceleration vector, and $\boldsymbol{u}$ $=$ nodal displacement vector. For a linear system, free vibration will be of the harmonic form expressed as:

$$
\boldsymbol{u}=\boldsymbol{\phi}_{\boldsymbol{i}} \cos \omega_{i} t
$$

where, $\phi_{i}=$ eigenvector representing the mode shape of the $i$ th natural frequency, $\omega_{i}=i$ th natural circular frequency in radians per unit time, $t=$ time in $\mathrm{s}$. Substitution of Eq. (3) in Eq. (2) gives:

$$
(-\boldsymbol{M}+\boldsymbol{K}) \boldsymbol{\phi}_{\boldsymbol{i}}=0
$$


Eq. (4) is satisfied if either $\boldsymbol{\phi}_{i}=\boldsymbol{O}$ or the determinant $\left|-\omega^{2} \boldsymbol{M}+\boldsymbol{K}\right|$ is zero. The first option is trivial, therefore the solution is given by:

$$
\left|-\omega^{2} \boldsymbol{M}+\boldsymbol{K}\right|=0
$$

Eq. (5) is the characteristic equation that can be solved for up to $n$ values of $\omega^{2}$ and $n$ eigen vectors $\boldsymbol{\phi}_{i}$, where $n$ is the number of DOF (degrees of freedom). The natural frequencies $f$ in cycles per unit time are given by ANSYS instead of $\omega$. Ten natural frequencies and corresponding mode shapes were extracted for each model. The natural frequencies for the three models considered in the study are given in Table 1 .

Mode shapes of the first natural frequency for Model A tank when it was empty and filled with water up to $90 \%$ of its depth are shown in Figs. 5 and 6, respectively.

\subsection{Nonlinear Transient Dynamic Analysis}

Transient dynamic analysis is used to determine the response of a structure subjected to time dependent loads considering inertia and damping effects. It is also called time-history analysis. The basic equation of motion solved by the transient dynamic analysis is given by:

$$
M \ddot{u}+\boldsymbol{C u}+\boldsymbol{K u}=\boldsymbol{F}(\boldsymbol{t})
$$

where, $\boldsymbol{M}=$ mass matrix, $\boldsymbol{C}=$ damping matrix, $\boldsymbol{K}=$ stiffness matrix, $\ddot{\boldsymbol{u}}=$ nodal acceleration vector, $\dot{\boldsymbol{u}}=$ nodal velocity vector, $\boldsymbol{u}=$ nodal displacement vector, and $\boldsymbol{F}(\boldsymbol{t})=$ load vector varying with time $t$. At any given time, Eq. (6) can be thought of as a set of "static"

\begin{tabular}{|c|c|c|c|c|c|c|}
\hline \multirow{2}{*}{ Frequency No. } & \multicolumn{2}{|c|}{ Model A steel tanks } & \multicolumn{2}{|c|}{ Model B steel tanks } & \multicolumn{2}{|c|}{ Model C steel tanks } \\
\hline & Empty & Water at $90 \%$ depth & Empty & Water at $90 \%$ depth & Empty & Water at $90 \%$ depth \\
\hline$\overline{1}$ & 2.83 & 1.22 & 4.51 & 1.45 & 10.63 & 3.27 \\
\hline 2 & 3.06 & 1.39 & 4.70 & 1.47 & 10.93 & 4.26 \\
\hline 3 & 4.00 & 2.25 & 4.74 & 1.64 & 13.29 & 5.07 \\
\hline 4 & 4.06 & 2.31 & 5.22 & 1.70 & 13.50 & 5.99 \\
\hline 5 & 5.48 & 3.31 & 5.50 & 1.86 & 16.91 & 8.03 \\
\hline 6 & 7.21 & 3.71 & 6.00 & 2.00 & 21.10 & 8.22 \\
\hline 7 & 7.33 & 4.90 & 6.91 & 2.24 & 21.43 & 12.41 \\
\hline 8 & 7.51 & 5.21 & 7.00 & 2.61 & 26.78 & 14.03 \\
\hline 9 & 7.87 & 5.42 & 8.18 & 2.79 & 27.16 & 17.26 \\
\hline 10 & 8.22 & 5.93 & 9.23 & 3.33 & 28.13 & 21.29 \\
\hline
\end{tabular}

Table 1 Natural frequencies $(f)$ in cycles/s $(\mathrm{Hz})$.

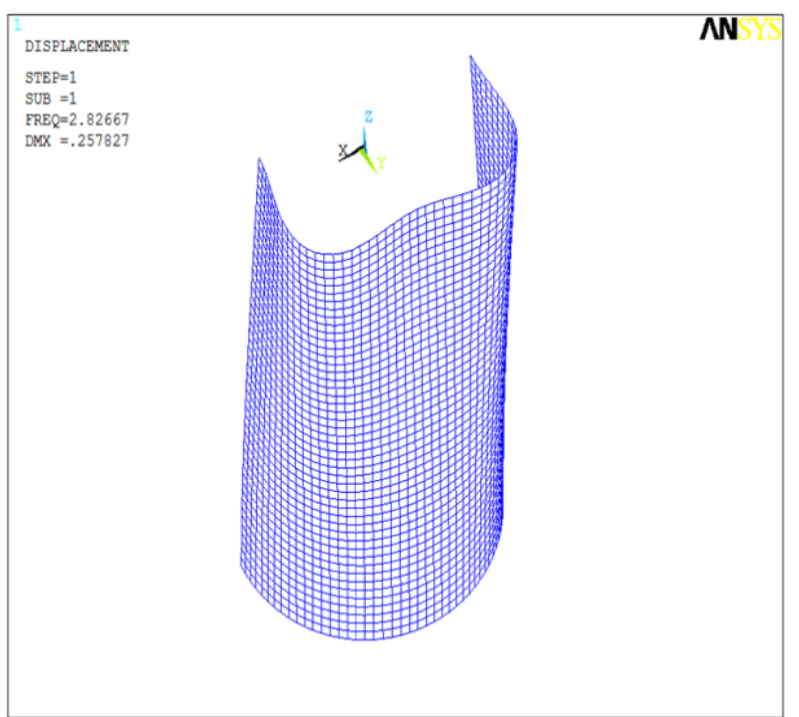

Fig. 5 First buckling mode for empty cylindrical tank Model A.

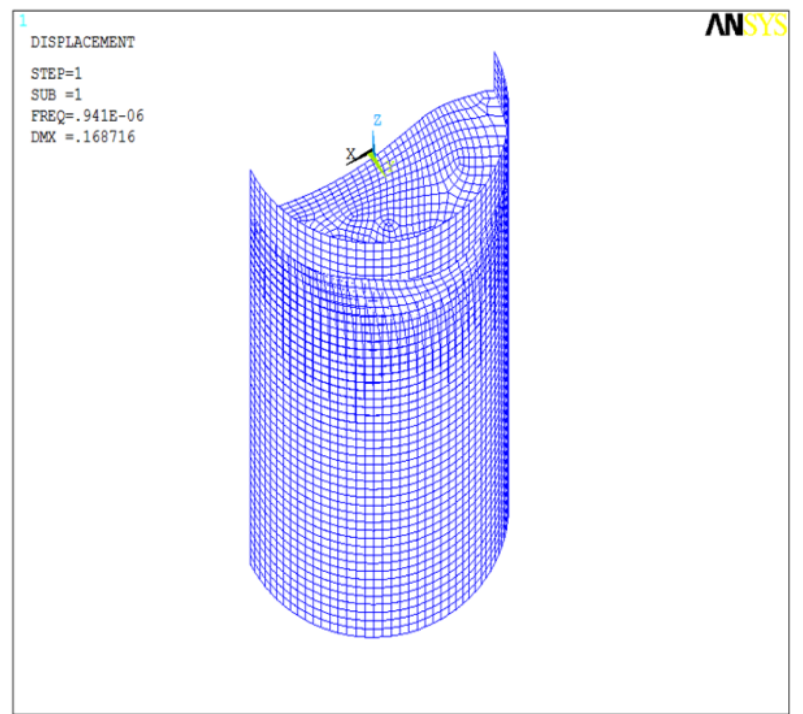

Fig. 6 First buckling mode of Model A tank with 90\% water depth. 
equilibrium equations that also take into account inertia ( $\boldsymbol{M} \ddot{\boldsymbol{u}})$ and damping force $(\boldsymbol{C} \dot{\boldsymbol{u}})$. The ANSYS program uses the Newmark time integration method to solve Eq. (6) at a discrete time point. The Newmark method uses finite difference expansions in the time interval $\Delta t$, in which it is assumed that:

$$
\begin{gathered}
\boldsymbol{u}_{\boldsymbol{n}+\mathbf{1}}^{\cdot}=\boldsymbol{u}_{\boldsymbol{n}}+\left[(1-\delta) \ddot{\boldsymbol{u}}_{\boldsymbol{n}}+\delta \boldsymbol{u}_{\boldsymbol{n}+\mathbf{1}}^{\ddot{*}}\right] \Delta t \\
\boldsymbol{u}_{\boldsymbol{n}+\mathbf{1}}=\boldsymbol{u}_{\boldsymbol{n}}+\boldsymbol{u}_{\boldsymbol{n}} \Delta t+\left[\left(\frac{1}{2}-\alpha\right) \ddot{\boldsymbol{u}}_{\boldsymbol{n}}+\alpha \boldsymbol{u}_{\boldsymbol{n}+\mathbf{1}}^{\cdot .}\right] \Delta t^{2}
\end{gathered}
$$

where, $\alpha, \delta$ are the Newmark integration parameters; $\boldsymbol{u}_{\boldsymbol{n}}, \boldsymbol{u}_{\boldsymbol{n}}$, and $\ddot{\boldsymbol{u}}_{\boldsymbol{n}}$ are the nodal displacement, velocity, and acceleration respectively at time $t_{n}$. Similarly, $\boldsymbol{u}_{\boldsymbol{n}+\mathbf{1}}, \boldsymbol{u}_{\boldsymbol{n}+\mathbf{1}}$, and $\boldsymbol{u}_{\boldsymbol{n}+\mathbf{1}}$ are the nodal displacement, velocity, and acceleration at the time $t_{n+1} ; \Delta t=t_{n+1}-t_{n}$. The governing Eq. (6) is written at time $t_{n+1}$ to calculate $\boldsymbol{u}_{\boldsymbol{n}+\boldsymbol{1}}$ as follows:

$$
M u_{n+1}^{\ddot{n}}+C u_{n+1}^{\cdot}+K u_{n+1}=F(t)
$$

The quantity $\boldsymbol{u}_{\boldsymbol{n}+\boldsymbol{1}}$ is calculated by rearranging Eqs. (7) and (8) as follows:

$$
\begin{gathered}
\boldsymbol{u}_{\boldsymbol{n}+1}^{.0}=a_{0}\left(\boldsymbol{u}_{n+1}-\boldsymbol{u}_{\boldsymbol{n}}\right)-a_{2} \ddot{\boldsymbol{u}}_{\boldsymbol{n}}-a_{3} \ddot{\boldsymbol{u}_{n}} \\
\boldsymbol{u}_{\boldsymbol{n}+\mathbf{1}}^{\cdot}=\boldsymbol{u}_{\boldsymbol{n}}+a_{6} \ddot{\boldsymbol{u}}_{\boldsymbol{n}}+a_{7} \boldsymbol{u}_{\boldsymbol{n}+1}
\end{gathered}
$$

where, $a_{0}=\frac{1}{\alpha \Delta t^{2}}, \quad a_{2}=\frac{1}{\alpha \Delta t}, \quad a_{3}=\frac{1}{2 \alpha}-1, a_{6}=$ $\Delta t(1-\delta)$, and $a_{7}=\delta \Delta t$.

$\boldsymbol{u}_{\boldsymbol{n}+\mathbf{1}}^{\ddot{*}}$ in Eq. (10) can be substituted in Eq. (11), and the equations for $\boldsymbol{u}_{\boldsymbol{n}+\mathbf{1}}^{\ddot{ }}$ and $\boldsymbol{u}_{\boldsymbol{n}+\mathbf{1}}$ are thus expressed in terms of unknown $\boldsymbol{u}_{\boldsymbol{n}+\boldsymbol{1}}$ and the known displacements $\boldsymbol{u}_{\boldsymbol{n}}$, velocities $\boldsymbol{u}_{\boldsymbol{n}}$, and accelerations $\ddot{\boldsymbol{u}}_{\boldsymbol{n}}$ at the time $t_{n}$. The equations for $\boldsymbol{u}_{\boldsymbol{n}+\mathbf{1}}$ and $\boldsymbol{u}_{\boldsymbol{n}+\mathbf{1}}$ are then substituted in Eq. (9) to get:

$$
\begin{aligned}
& \qquad\left(a_{0} \boldsymbol{M}+a_{1} \boldsymbol{C}+\boldsymbol{K}\right) \boldsymbol{u}_{\boldsymbol{n}+\mathbf{1}}=\boldsymbol{F}(\boldsymbol{t})+\boldsymbol{M}\left(a_{0} \boldsymbol{u}_{\boldsymbol{n}}+\right. \\
& \left.a_{2} \boldsymbol{u}_{\boldsymbol{n}}+a_{3} \ddot{\boldsymbol{u}}_{\boldsymbol{n}}\right)+\boldsymbol{C}\left(a_{1} \boldsymbol{u}_{\boldsymbol{n}}+a_{4} \boldsymbol{u}_{\boldsymbol{n}}+a_{5} \ddot{\boldsymbol{u}}_{\boldsymbol{n}}\right) \\
& \text { where, } a_{1}=\frac{\delta}{\alpha \Delta t}, \quad a_{4}=\frac{\delta}{\alpha}-1 \text {, and } a_{5}=\frac{\Delta t}{2}\left(\frac{\delta}{\alpha}-2\right) .
\end{aligned}
$$

The displacements $\boldsymbol{u}_{\boldsymbol{n}+\mathbf{1}}$ are obtained from Eq. (12). Eqs. (10) and (11) are used to update the velocities and accelerations. The Newmark parameters are related to the input as follows:

$$
\alpha=\frac{1}{4}(1+\gamma)^{2}, \text { and } \delta=\frac{1}{2}+\gamma
$$

where, $\gamma$ is the amplitude decay factor. The solutions of Eq. (9) are stable if $\gamma \geq 0$ [14]. The default value of $\gamma$ is 0.005 .
The analysis was performed for the empty tank models and for the tanks when they were filled with water up to $90 \%$ depth. The cylindrical shell was formed by using ANSYS Shell Element 181, whereas the fluid content in the tanks was modeled with ANSYS Fluid 80 elements to simulate water. The Fluid 80 element input data include eight nodes and the isotropic material properties. The bulk modulus of water is taken as 300,000 psi $(2,068.5 \mathrm{MPa})$, and the viscosity property of water to compute the damping matrix is taken as $1.639 \times 10^{-7}$ lbf.-sec./in. ${ }^{2}\left(1.13 \times 10^{-9}\right.$ $\mathrm{N}$-sec. $/ \mathrm{mm}^{2}$ ). Dynamic buckling analysis of the tank-fluid system was modeled with geometric and material nonlinearities. Large deformation and elasto-platic properties, and stress-strain properties were assumed for the cylindrical shell. Plasticity was included using bilinear isotropic hardening with yield stress of $50 \mathrm{psi}(345 \mathrm{MPa})$ and a tangent modulus of $2 \times$ $10^{6} \mathrm{psi}(13,790 \mathrm{MPa})$. The earthquake force was input to the base of the tanks as time-history acceleration corresponding to the El Centro earthquake [15] shown in Fig. 7. The north-south component having the maximum ground acceleration (PGA) of $0.319 \mathrm{~g}$ was used. The first $7.04 \mathrm{~s}$ of the earthquake record was used because the maximum amplitudes of the earthquake occurred before that period.

For determining the dynamic buckling load, a qualitative but fairly well defined criterion [16] was used. This criterion is based on computing the time-dependent responses for gradually rising load amplitudes (rising PGA for a particular earthquake in the case of earthquakes). When the response, measured at the control point, shows a steep rise in the maximum amplitude for a small change in the load amplitude (PGA for earthquake), it is assumed that the buckling load has reached. It was found that, for empty tanks, the critical PGA was unrealistically high. The Models A, B, and C buckled at PGA values of $21 \mathrm{~g}, 28 \mathrm{~g}$, and $90 \mathrm{~g}$, respectively. This means that the empty tanks will not buckle under the influence of any possible real world earthquake. 


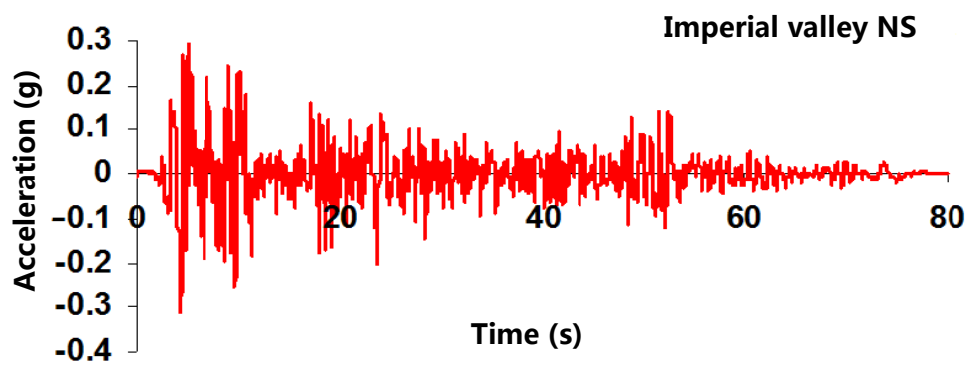

Fig. 7 North-south horizontal ground acceleration at El Centro, California.

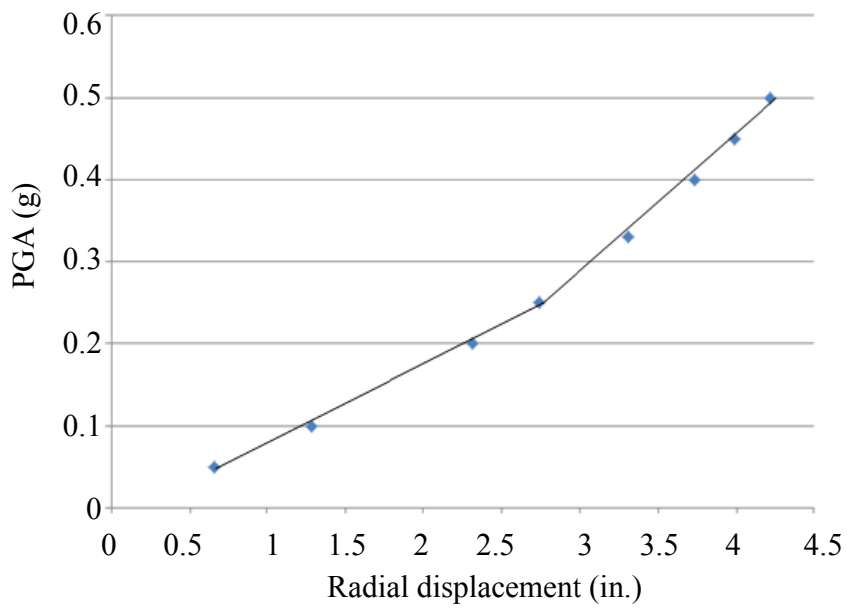

Fig. 8 Pseudo equilibrium path for the critical Node 2 of Model A tank filled with water up to $90 \%$ depth.

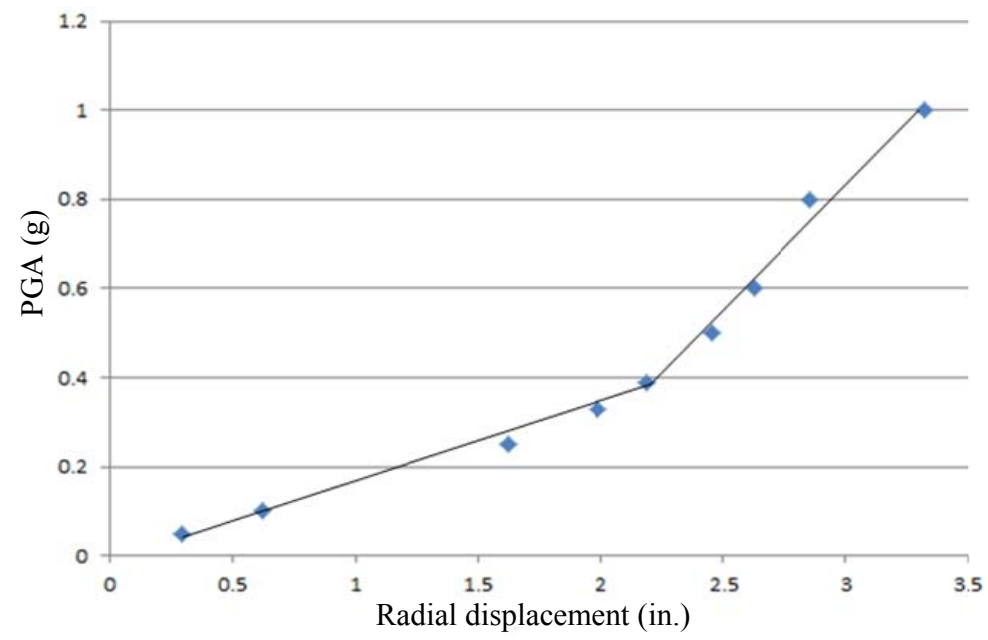

Fig. 9 Pseudo equilibrium path for the critical Node 2 of Model B tank filled with water up to $90 \%$ depth.

The tanks were also analyzed when they were containing water up to $90 \%$ depth of the tank. The displacements at the top Node 2 versus PGA (varying PGA for the El Centro earthquake) are plotted to form the "pseudo equilibrium path" for the Model A tank in Fig. 8. The curve follows an initially stable path and then the slope of the curve changes at the critical load because of reduction in the stiffness of the tank. The critical PGA for the Model A tank is $0.25 \mathrm{~g}$ in Fig. 8, similarly, the critical PGA for the Model B tank is $0.39 \mathrm{~g}$ shown in Fig. 9. The nodal deformations are shown for the Models A and B tanks filled with water up to $90 \%$ depth in Figs. 10 and 11 at $6.22 \mathrm{~s}$ and $5.84 \mathrm{~s}$, respectively. 


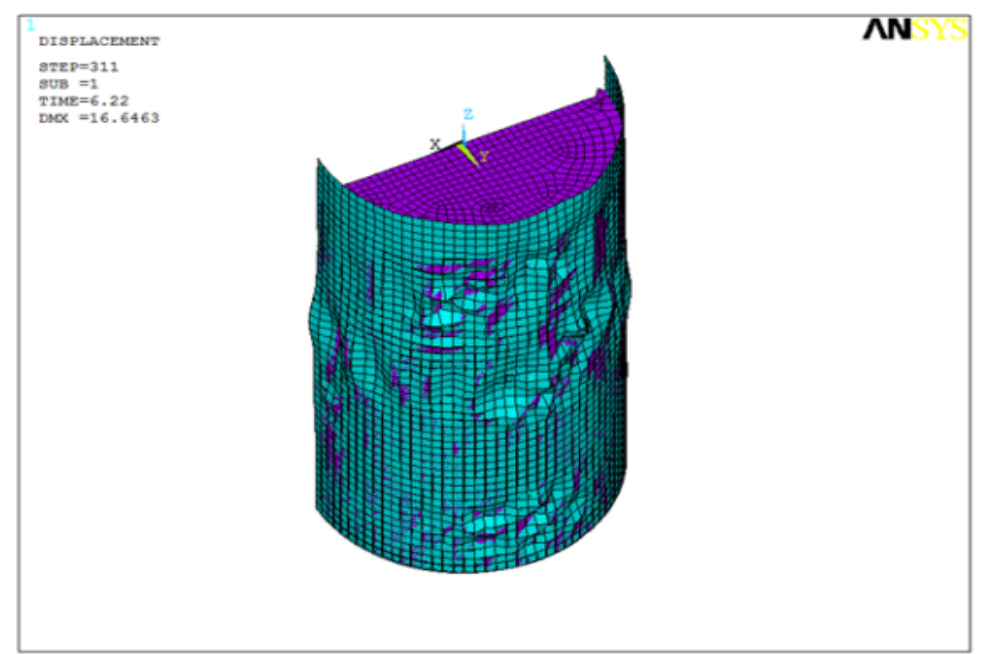

Fig. 10 Nodal deformations for Model A tank at $6.22 \mathrm{~s}$ and PGA $=0.45 \mathrm{~g}$ with water up to $90 \%$ depth.

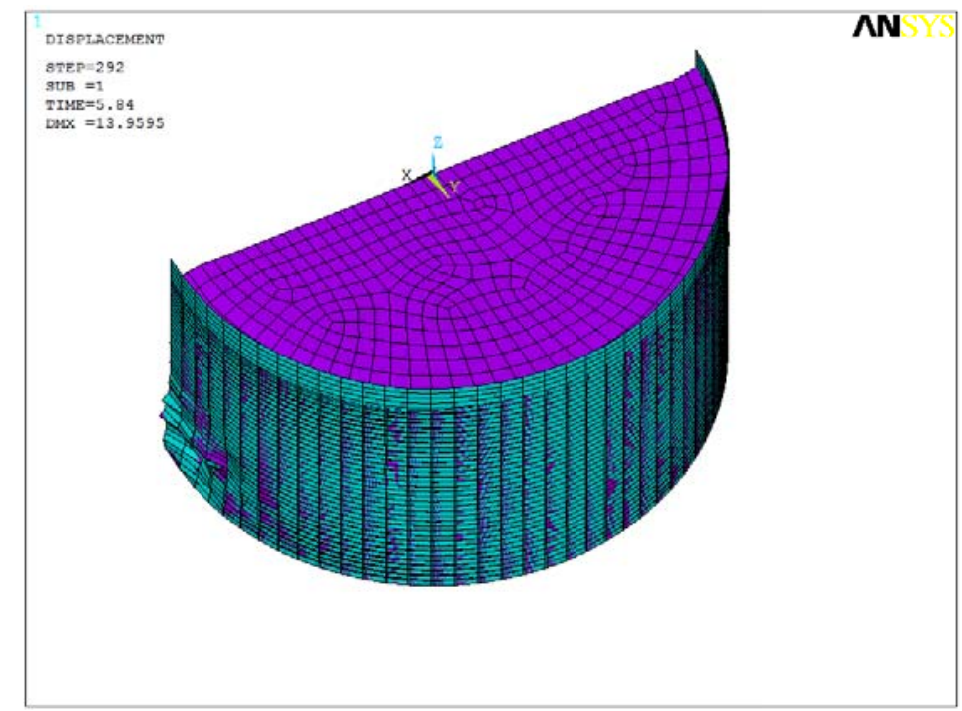

Fig. 11 Nodal deformations for Model B tank at $5.84 \mathrm{~s}$ and PGA = 1.0g with water up to $90 \%$ depth.

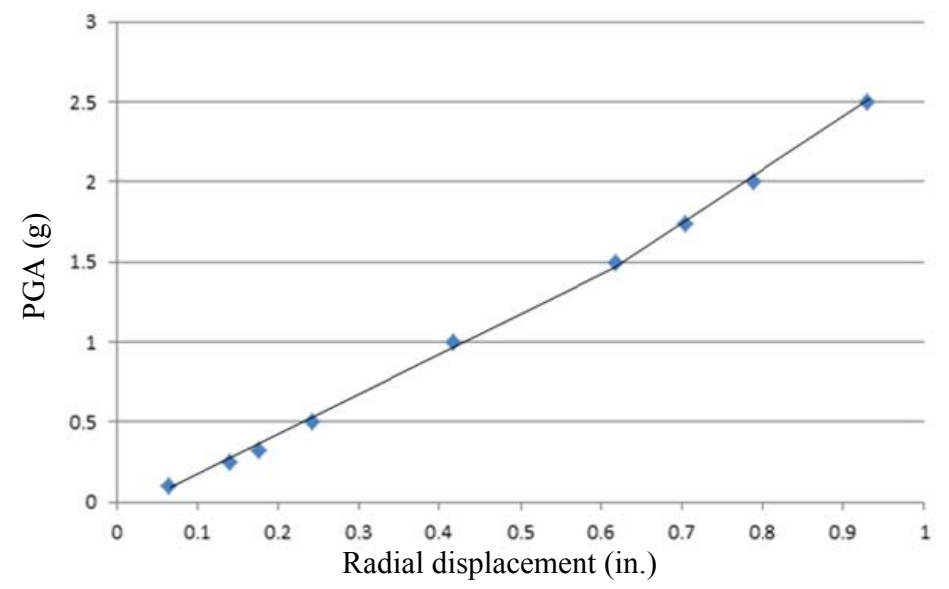

Fig. 12 Pseudo equilibrium path for the critical Node 2 of Model C tank filled with water up to $90 \%$ depth. 
The critical PGA for the Model C tank is $1.5 \mathrm{~g}$ shown in Fig. 12. The study supports the previous findings [17] that for tanks the critical PGA decreases with decrease in natural frequencies.

\section{Conclusions}

For static buckling analysis, the theoretical results compared well with the numerical analysis by the finite element method. Hence the finite element modeling can be used to study the stability of cylindrical shells under seismic loading.

It is interesting to note that static buckling occurs when the tanks are empty whereas dynamic instability occurs in tanks when they have liquid stored in them because of added mass. Finite element analysis results show that the dynamic buckling occurs for empty tanks at very high PGA which are unrealistic even for major earthquakes.

Nonlinear time history analysis results of three cylindrical tanks with different dimensions show that: Model A $(H / D=2.0$ and $D / t=960.0)$ had buckling at PGA of $0.25 \mathrm{~g}$; the Model $\mathrm{B}(H / D=0.56$ and $D / t=$ 1760.67) had the buckling at PGA of 0.39g; and Model $\mathrm{C}(H / D=1.0$ and $D / t=640.0)$ buckled at the PGA of $1.50 \mathrm{~g}$. It means that when the $H / D$ ratio reduced by two times (i.e., from 2 to 1), the PGA for the buckling increased by six times (increase from $0.25 \mathrm{~g}$ to $1.5 \mathrm{~g}$ ). Hence $H / D$ ratio plays an important role in the earthquake stability design of over ground steel tanks.

\section{References}

[1] Langhaar, H. L., and Boresi, A. P. 1956. Buckling and Post-buckling Behavior of Cylindrical Shells Subjected to External Pressure. Report No. 93, Department of Theoretical and Applied Mechanics, University of Illinois.

[2] Bushnell, D., and Miller, E. 1984. "Elastic-Plastic Collapse of Axially Compressed Cylindrical Shells: A Brief Survey with Particular Application to Ring-Stiffened Cylindrical Shells with Reinforced Opening." Journal of Pressure Vessel Technology 106 (1): 122-8.

[3] Jerath, S., and Porter, S. R. 1990. "Buckling Load of Cylindrical Shells by Finite Element Large Deflection Analysis." In Proceedings of 1990 SSRC (Structural
Stability Research Council) Annual Technical Session, 195-204.

[4] Cooper, T. W., and Wachholz, T. P. 1999. "Optimizing Post-earthquake Lifeline System Reliability." In Proceedings of the 5th US Conference on Lifeline Earthquake Engineering, 878-86.

[5] Veletsos, A. S., and Yang, J. Y. 1977. "Earthquake Response of Liquid Storage Tanks-Advances in Civil Engineering through Mechanics." In Proceedings of the Second ASCE (American Society of Civil Engineers) Engineering Mechanics Specialty Conference, 1-24.

[6] Haroun, M. A., and Housner, G. W. 1981. "Earthquake Response of Deformable Storage Tanks." Journal of Applied Mechanics 48 (2): 411-8.

[7] Chalhoub, M. S., and Kelly, J. M. 1990. "Shake Table Test of Cylindrical Water Tanks in Base Isolated Structures." Journal of Engineering Mechanics 116 (7): 1451-72.

[8] Bo, L., and Jia-xiang, T. 1994. "Vibration Studies of Base Isolated Liquid Storage Tanks." Computers and Structures 52 (5): 1051-9.

[9] Malhotra, P. K. 1997. "Method for Seismic Base Isolation of Liquid Storage Tanks." Journal of Structural Engineering 123 (1): 1051-9.

[10] Shenton, H. W., and Hampton, F. P. 1999. "Seismic Response of Isolated Elevated Water Tanks." Journal of Structural Engineering 125 (9): 965-76.

[11] Virella, J. C., Godoy, L. A., and Suarez, L. E. 2006. "Dynamic Buckling of Anchored Steel Tanks Subjected to Horizontal Earthquake Excitation." Journal of Constructional Steel Research 62 (6): 521-31.

[12] Sezen, H., Livaoglu, R., and Dogangun, A. 2008. "Dynamic Analysis and Seismic Performance Evaluation of Above Ground Liquid Containing Tanks." Engineering Structures 30 (3): 794-803.

[13] ANSYS, Inc. 2007. ANSYS Reference Documentation. USA: ANSYS, Inc.

[14] Zienkiewicz, O. C. 1977. The Finite Element Method. New York: McGraw-Hill.

[15] Chopra, A. K. 2012. Dynamics of Structures-Theory and Applications to Earthquake Engineering. New York: Prentice hall.

[16] Budiansky, B., and Roth, S. 1962. "Axisymmetric Dynamic Buckling of Clamped Shallow Spherical Shells." In NASA (National Aeronautics and Space Administration) Collected Papers on Stability of Shell Structures, 597-606.

[17] Jerath, S., and Qiao, W. 2009. "Dynamic Stability of Water Tanks." Presented at the 2009 Joint ASCE-ASME-SES (American Society of Civil Engineers-American Society of Mechanical Engineers-Society of Engineering Science) Conference on Mechanics and Materials, Blacksburg, USA. 